\title{
Evaluation of environmental and economic effectiveness of the Cross Compliance 4.3 Standard 'Maintenance of olive groves and vineyards in good vegetative conditions'
}

Luigi Sansone, ${ }^{1}$ Antonio Melchiorre Carroni, ${ }^{2}$ Marco Fedrizzi, ${ }^{3}$ Elena Santilli, ${ }^{4}$ Giuseppina Pipitone, ${ }^{1}$ Mauro Pagano, ${ }^{3}$ Giulio Sperandio, ${ }^{3}$ Mirko Guerrieri, ${ }^{3}$ Daniele Puri, ${ }^{3}$ Francesco Zaffina, ${ }^{4}$ Mauro Salis, ${ }^{2}$ Paola Ruda, ${ }^{2}$ Thomas Patrizio Vatrano, ${ }^{4}$ Paolo Bazzoffi, 5 Samanta Zelasco ${ }^{4}$

1CREA-VIT Council for Agricultural Research and Economics, Research Unit for Wine-growing, Conegliano (TV) ${ }^{2}$ CREA-AAM Council for Agricultural Research and Economics, Research Unit for Agro-pastoral Systems in Mediterranean Environment, Sanluri, Medio Campidano

${ }^{3}$ CREA-ING Council for Agricultural Research and Economics, Research Unit for Agricultural Engineering, Monterotondo (RM) ${ }^{4}$ CREA-OLI Council for Agricultural Research and Economics, Research Centre for Olive Growing and Olive Product Industry, Rende (CS)

${ }^{5}$ CREA-ABP Council for Agricultural Research and Economics, Research Centre for Agro-biology and Pedology, Florence, Italy

Corresponding author: Luigi Sansone,

E-mail: luigi.sansone@crea.gov.it

Key words: Cross-compliance; rural development; Standard 4.3; pruning and trimming; competitiveness.

Work undertaken within the MO.NA.CO. Project (National monitoring network for the environmental effectiveness of cross-compliance and the differential of competitiveness induced from it charged to agricultural enterprises) funded by the Ministry of Agricultural, Food and Forestry policies (MiPAAF) within the National Rural Network project under Action 1.2.2 'Interregional Development Laboratories' of the operational programme known as 'National Rural Network 2007-2013', Coord. Paolo Bazzoffi.
Acknowledgments: a special thank to Mr. Santo Salvador from CREA-VIT, Dr. Domenico Turco, Mr. Antonio Ripoli and Mr. Antonio Fiorita from CREA-OLI, Mr. Maurizio Pitzalis and Mr. Michele Lilliu from CREA-AAM experimental farm for the technical assistance.

(C) Copyright L. Sansone et al., 2015

Licensee PAGEPress, Italy

Italian Journal of Agronomy 2015; 10(s1):691

doi:10.4081/ija.2015.691

This article is distributed under the terms of the Creative Commons Attribution Noncommercial License (by-nc 3.0) which permits any noncommercial use, distribution, and reproduction in any medium, provided the original author(s) and source are credited.

\begin{abstract}
This paper reports the first observations made in three farms of the Council for Agricultural Research and Economics (CREA) relating to the environmental monitoring of the Standard 4.3 maintenance of olive groves and vineyards in good vegetative conditions and analysis of differential of competitiveness for both crops.
\end{abstract}

\section{Introduction}

The olive growing and viticulture are called to meet the objective 4 provided by the Ministerial Decree of $22^{\text {nd }}$ December 2009, through the application of the cross-compliance Standard 4.3. It refers specifically to the maintenance of olive groves and vineyards in good vegetative condition, in order to ensure a minimum level of maintenance and avoid the deterioration of habitats (decrease in the risk of weeds spread and in the risk of fire) and the abandonment. The standard provides the pruning execution at least annually and every five years for the grapevine and olive tree respectively. The standard also provides that a cleaning of the soil from weeds, brambles and suckering (in this case only for olive tree) must be guaranteed at least every three years. This work, conducted at three monitoring sites of CREA research facilities, two for olive tree and one for the grapevine, reports the first results concerning the measurement of the inflammable biomass indicator and the agro-environmental data for the analysis of the economic differential of competitiveness in relation to the application of the standard. 


\section{Materials and methods}

For the grapevine, the monitoring started in 2013 at the CREA-VIT farm located in Spresiano (Treviso). In the 20-year-old experimental vineyard, cultivated with the variety Glera and grown by Sylvoz, two plots have been identified (Counterfactual plot and factual plot), each consisting of 5 rows of grapevines and the total size of $1170 \mathrm{~m}^{2}$. The measurements were taken on 30 plants distributed in the three central rows ( 10 plants / row) of the plot. Annual pruning as provided by standard 4.3 was applied to the factual plot (F) maintaining the kind of pruning fit the type of farming that already existed while a state of disrepair was simulated in the counterfactual plot (CF), making pruning only in February 2015. Winter pruning was carried out manually with the aid of electric scissors type Felco82; the weight of the pruning residues was measured by dynamometer. The evaluation of the amount of biomass to the soil was conducted using the method of the square: areas of $1 \mathrm{~m}^{2}$ of surface were sampled randomly, for the entire length of the rows at intervals of $15 \mathrm{~m}$. In the $\mathrm{CF}$ plot, launches were made in mid-May and early August of each year, while in the F plot they were made only once, at the last cut of the grassing in 2014. The biomass samples were dried in an oven at $60^{\circ} \mathrm{C}$ until constant weight was reached. For the olive tree, the monitoring started in 2013, and is still taking place at the fields located next to the CREA-OLI, Rende (Cosenza) and CREA-AAM, Sanluri (Medio Campidano). The CREAOLI's olive grove is characterized by Carolea cultivar and it is 25 years old. The olive grove of CREA-OLI is 25 years old while the one of CREAAAM is about 50 years old; the cultivars present in these olive groves are typical of the area and are Carolea and Nera di Villacidro, respectively. Both the olive groves show a vase form as training. Pruning residues have been evaluated from different rounds (from 1 to 5 years) as potentially inflammable biomass. The pruning so far performed has been conducted manually by two operators through the use of chain saw, jig saw and cutting machines equipped with rod facilitator. The pruning residues of each thesis (from one to five-year pruning) were weighed directly in the field with a steelyard. Similarly, suckers have been removed every year, two years and three years at the CREA-OLI, while they were collected only every three years at the CREA-AAM. The agricultural operation was performed by an operator using a hatchet. The evaluation of the amount of biomass to the soil has been performed as described above for the grapevine but with intervals of $25 \mathrm{~m}$ over the entire surface area $\left(100 \mathrm{~m}^{2}\right)$. In the F plot it has been carried out to detect the amount of biomass after three years of grassing while in CF plot it has controlled the grassing at least once a year with the shredding operation, keeping the grassing all year long. To assess the competitiveness gap, the cost of mechanical farming operations was calculated using data monitored by the two operative units during the farming operations. The processing of the data collected during the farming operations has allowed the definition of the time of work through the recommendation of the Italian Association of Rural Engineering (A.I.G.R.) IIla R1 (Manfredi, 1971) that considers the methodology of Commission Internationale de l'Organisation Scientifique du Travail en Agriculture (C.I.O.S.T.A.). The surveys carried out in the field have been related to the effective work time (TE) and to the turning accessory time (TAV), whose sum is the net working time (TN). The assessment of hourly cost of the machines and equipment, was calculated using an analytical methodology (Biondi, 1981) and technical standards to which this refers (ASAE, 2003a, 2003b), in order to determine the cost per hectare of the agricultural operations. The datum relating to the remuneration of farm labour, used in the above method, is the average of the values fixed by Confederazione Italiana Agricoltori in the national collective agreement in force for the qualification of super specialized worker, level A, Area 1, and super skilled worker, level A, Area 2, referred to the monitored provinces.
Thanks to this information it was possible to calculate the total cost of the agricultural operation to be performed in case of compliance with the standard. In case of non compliance with the standard, since it refers to a situation of total abandonment, the cost incurred by the farmer is zero. Therefore, the economic competitiveness gap coincides with the sum of the costs necessary for the realization of mechanized and manual cultural operations necessary to comply with the standard. In the case of the olive tree, as the standard requires the execution of cultural operations with different frequencies (every three years and every five years), it was hypothesized a period of 15 years which is the shortest time cycle that, when repeated, it always contains the same mechanized and manual cultural operations. For the mechanized and manual cultural operations such as pruning, raking, and sawing brushwood olive, suckering and contemporary shredding of grass cover and olive brushwood, cost values used are those monitored by the mentioned operative unit, while for the cost value of the grass cover shredding, being an agricultural operation not influenced by the type of crop, it was used the average cost of similar cultural operations monitored in the project MONACO. The cumulative values of annual costs for the two areas of monitoring, were discounted by the financial function NPV (Net Present Value). The farmer who is not compliant with the standard, does not support any cost, and so the value of the resulting NPV represents the cumulative value of the competitiveness gap ( $\left.€ \mathrm{ha}^{-1}\right)$ in the period of fifteen years. By calculating the constant annual installments it has been determined the annual value of the competitiveness gap in $€ \mathrm{ha}^{-1}$ year-1 for the two operatives unit monitored.

\section{Results}

In the vineyard, data for the annual winter pruning in the $\mathrm{F}$ plot have shown a likely 'year effect' that has favoured the year 2015 in terms of the amount of wood removed per hectare (Table 1).

This production, which refers to the vegetative-productive activity in 2014, was basically greater than that of the years 2013 and 2014. The amount of wood obtained in the CF plot at the end of a period of not pruning lasted three consecutive years, was equal to $5,95 \mathrm{Mg} \mathrm{ha}^{-1}$, being higher than the average of the three years of pruning in the $\mathrm{F}$ plot, equal to $5,5 \mathrm{Mg} \mathrm{ha}^{-1}$. Therefore, in terms of produced and potentially inflammable biomass, in case it reaches a state of dehydration more stringent than the measurement time, the absolute deviation $0,90 \mathrm{Mg} \mathrm{ha}^{-1}$ of the CF plot, used as a basic indicator, points toward a positive evaluation of the effectiveness of the standard. In olive tree, the amount of pruning residues produced on average each year per hectare with the pruning rounds detected (one, two, three and five years) is shown in Table 2.

The five-year pruning has a significantly impact on the amount of removable biomass than shorter pruning rounds $(\mathrm{P}=0.0001)$. In addition the five-year pruning has produced a wood residue with a diameter

Table 1. Amount of pruning residues in grapevine as it is: annual average data (factual) and average data after three cycles without pruning (counterfactual).

\begin{tabular}{lcc} 
CREA-VIT & Factual & Counterfactual \\
Year & $\left(\mathrm{Mg} \mathrm{ha}^{-1}\right)$ & $\left(\mathrm{Mg} \mathrm{ha}^{-1}\right)$ \\
2013 & 5.07 & \\
2014 & 4.67 & \\
\hline 2015 & 5.42 & 5.95 \\
Average & 5.05 & 5.95 \\
\hline
\end{tabular}


greater than $10^{-15} \mathrm{~cm}$ impossible to shred, with a medium amount of $5.74 \mathrm{Mg} \mathrm{ha}^{-1}$ increasing the potential risk of fire associated to pruning residues if not properly managed. This is confirmed by observations made at the CREA-AAM monitoring site where the average amount of yearly pruning residues per hectare after a five-year pruning round was 14.2 $\mathrm{Mg} \mathrm{ha}^{-1}$. Analyzing the amount of suckers removed on average each year, the difference between the annual and three-year thesis was significant $(\mathrm{P}=0.009)$ as confirmed by measurements conducted at the CREA-AAM site where the amount of suckers after three years was still higher than that recorded at CREA-OLI (Table 3).

In both years, the vineyard monitoring for the trimming, in the $\mathrm{CF}$ plot, considering the average annual datum, showed amore abundant production in 2013 with a value of $3.02 \mathrm{Mg} \mathrm{ha}^{-1}$ (Table 4). The biomass produced in the F plot, after three seasonal cycles in the absence of processing to the soil compared to the average $\mathrm{CF}$ resulted in a difference of $-0,33 \mathrm{Mg} \mathrm{ha}^{-1}$, used as an indicator, whereby it can be stated that the application of the standard, with the limits of the period considered, led to a lower production of inflammable biomass on the ground.

Furthermore, the annual datum of CF plot (Table 4) has always resulted higher than the single value detected in the $\mathrm{F}$ plot $(2.52 \mathrm{Mg}$ $\mathrm{ha}^{-1}$ ), confirming the depressing action exerted by herbaceous cover when not cut regularly. In olive tree, at the CREA-OLI monitoring site, the average amount of biomass to the soil found in the CF plot was 3.55 $\mathrm{Mg} \mathrm{ha}^{-1}$ greater than the one detected in the F plot of $2.6 \mathrm{Mg} \mathrm{ha}^{-1}$. This datum confirmed the depressing action exerted by the grassing when not cut for long periods. At the CREA-AAM site, instead the difference between $\mathrm{CF}$ and $\mathrm{F}$ plots was negative and amounted to $1.7 \mathrm{Mg} \mathrm{ha}^{-1}$ (Table 5).

Table 2. Amount of pruning residues in olive tree for different pruning rounds $\left(\mathrm{Mg} \mathrm{ha}^{-1}\right)$.

\begin{tabular}{lcccc} 
& $\begin{array}{c}\text { One- year } \\
\text { pruning* }\end{array}$ & $\begin{array}{c}\text { Two-year } \\
\text { pruning }\end{array}$ & $\begin{array}{c}\text { Three-year } \\
\text { pruning }\end{array}$ & $\begin{array}{c}\text { Five-year } \\
\text { pruning }\end{array}$ \\
CREA-OLI & $0.8^{\mathrm{ab}}$ & $0.5^{\mathrm{a}}$ & $2.5^{\mathrm{b}}$ & $8.2^{\mathrm{c}}$ \\
CREA-AAM & & & & 14.21 \\
\hline
\end{tabular}

*Two-year average datum

Table 3. Amount of suckers from different thesis $\left(\mathrm{mg} \mathrm{ha}^{-1}\right)$.

\begin{tabular}{lccc} 
& $\begin{array}{c}\text { One-year } \\
\text { suckering* }\end{array}$ & $\begin{array}{c}\text { Two-year } \\
\text { suckering }^{\circ}\end{array}$ & $\begin{array}{c}\text { Three-year } \\
\text { suckering }^{\circ}\end{array}$ \\
CREA-OLI & $0.3^{\mathrm{a}}$ & $0.57^{\mathrm{ab}}$ & $0.96^{\mathrm{b}}$ \\
CREA-AAM & & & $0.7^{\mathrm{b} * *}$ \\
\hline
\end{tabular}

*Three-year average datum; ${ }^{\circ}$ two-year average datum.i.

Table 4. Biomass to the soil $\left(\mathrm{mg} \mathrm{ha}^{-1} \mathrm{dm}\right)$ in the vineyard: annual farming average datum (counterfactual) and average datum after two years without tillage (factual).

\begin{tabular}{lcc} 
CREA-VIT & $\begin{array}{c}\text { Factual } \\
\left(\mathrm{Mg} \mathrm{ha}^{-1}\right)\end{array}$ & $\begin{array}{c}\text { Counterfactual } \\
\left(\mathrm{Mg} \mathrm{ha}^{-1}\right)\end{array}$ \\
Year 2013 & & \\
I cut & & 3.12 \\
II cut & 2.92 \\
Average & 3.02 \\
Year 2014 & \\
I cut & & 2.57 \\
II cut & 2.52 & 2.77 \\
Average & & 2.67 \\
\hline Total average & 2.52 & 2.85 \\
\hline
\end{tabular}

For the vineyard, the costs incurred for the mechanized and manual cultural operations imposed by the standard are given in Table 6 .

The economic competitiveness gap coincides with the total costs incurred in compliance with the standard and amounts to $551.70 € \mathrm{ha}^{-}$ ${ }^{1}$ year $^{-1}$, which corresponds to $0.25 €$ plant $^{-1}$ year $^{-1}$. For the olive grove, the cultures in the monitored farms differ in number, size and age of the olive trees: the Sanluri operative unit has an olive grove characterized by trees whose age and dimensions are higher and has a sixth10by $^{-1} 0$-metre plant, corresponding to a density of 100 trees per hectare. In the olive grove of Rende (Cosenza) operative unit there are 417 trees per hectare, whose age and dimensions are lower, they are planted out by means of a narrower plant equal to 6 by 4 metres. The costs incurred in the two experimental sites concerning the mechanized and manual cultural operations provided for by the standard are reported in Table 7. The frequency of the agricultural operation in the period considered is shown in Table 8. The annual competitiveness gap for a single olive tree is shown in Table 9.

\section{Discussions and Conclusions}

The measured parameters in the environmental monitoring of the standard 4.3 were as follows: biomass to the soil $\left(\mathrm{Mg} \mathrm{ha}^{-1}\right)$, pruning residues $\left(\mathrm{Mg} \mathrm{ha}^{-1}\right.$ year $\left.^{-1}\right)$ and suckers $\left(\mathrm{Mg} \mathrm{ha}^{-1}\right.$ year $\left.{ }^{-1}\right)$ all attributable to the basic indicator "inflammable biomass". The parameter value "biomass to the soil" has confirmed a positive evaluation of the effectiveness of the standard in at least two out of three sites monitored, regardless of the considered crop. For the grapevine, measurement of pruning residues parameter provided positive values toward the effectiveness of the standard. For the olive the amount of biomass resulting from five-year pruning has produced an average amount of biomass per year significantly greater than that produced by the other rounds of pruning. Moreover, the production of pruning residues impossible to shred, obtained with this cycle of pruning increases the potential fire hazard in some olive growing areas if it cannot be removed (since it is often burned), increasing the risk of fungal infections if left on the edge of the olive grove, and the competitiveness differential. In the

Table 5. Biomass to the soil $\left(\mathrm{Mg} \mathrm{ha}^{-1} \mathrm{dm}\right)$ in the olive groves at the monitoring sites CREA-OLI and CREA-AAM.

\begin{tabular}{lcc} 
& $\begin{array}{c}\text { Factual } \\
\mathrm{Mg} \mathrm{ha}^{-1}\end{array}$ & $\begin{array}{c}\text { Counterfactual } \\
\mathrm{Mg} \mathrm{ha}^{-1}\end{array}$ \\
CREA-OLI & & \\
2013 & 2.6 & 4.2 \\
2014 & & 2.93 \\
Average & 2.6 & 3.55 \\
CREA-AAM & & \\
2014 & 4.5 & 2.8 \\
\hline
\end{tabular}

Table 6. Costs of cultural operations in vineyard $\left(€ \mathrm{ha}^{-1}\right.$ year $\left.^{-1}\right)$.

\begin{tabular}{|c|c|}
\hline Growing operations & $\begin{array}{l}\text { Machining costs } \\
\left(€ \text { ha }^{-1} \text { year }\right.\end{array}$ \\
\hline Pruning & 302.73 \\
\hline Removal pruning wood & 92.18 \\
\hline Tying of branches & 77.42 \\
\hline Shredding prunings & 79.37 \\
\hline Total cost of mechanical processing & 551.70 \\
\hline
\end{tabular}


case of other evaluated thesis, there is no production of this kind of pruning residues giving indication that also a three-year pruning can ensure the high effectiveness of the standard. Also the parameter suckers gave significant differences between the amount of suckers removed after three-year against those removed after one year. The amount of suckers produced on average each year in a three-year round was high in both sites of observation, in the presence of two different olive cultivars and planting distances. As for the evaluation of differential economic competitiveness, the economic analysis performed shows that the farmer who intends to adhere to the commitments of the Standard 4.3 related to the vineyards, incurs the annual cost amounting to $€ 551.70 \mathrm{ha}^{-1}$ year-1 for carrying out the manual and mechanical cultivation operations. Since the standard tends to combat the abandonment of vineyards, the amount of these costs represents the differential annual economic competitiveness. In the case of the olive, the values of the differential competitiveness, differ depending on the particular characteristics of the system considered. Examining the value of the differential annual competitiveness per surface unit for the CREA-OLI, the cost is more than double compared to that of CREA$\mathrm{AAM}$, but in relation to the number and characteristics of development of the existing plants, the value of the differential competitiveness is much lower than the CREA-OLI. Finally, in the case of the vineyard, the measured parameters showed the effectiveness of the application of the standard. Instead, in the case of the olive, the measured values relating to pruning residues and suckering suggest a reformulation of the judgment of effectiveness of the rule. The monitoring has made it possible to assess the cost incurred by a farmer in the case of adherence to the Standard 4.3 for the grapevine and the olive tree in relation to the considered monitoring sites.

Table 7. Mechanized and manual cultural operations costs monitored at the CREA-OLI and CREA-AAM operative units.

Mechanized and manual cultural operations cost $\left(€ h^{-1}\right)$
Adhesion to cross compliance regime
(CREA-OLlhesion to cross compliance regime $\left(€ \mathrm{ha}^{-1}\right)$
(CREA-AAM) $\left(€ \mathrm{ha}^{-1}\right)$

Pruning, raking and sawing brushwood olive

Suckering

Grass cover shredding

Contemporary shredding of grass cover and olive brushwood
4152.98

1591.55

122.10

182.64

67.05

107.17
67.05

110.50

Table 8. Cost and frequency of the agricultural operations in the period of time considered at the CREA-OLI and CREA-AAM operative units.

\begin{tabular}{|c|c|c|c|c|c|c|}
\hline Years & $\begin{array}{l}\text { Three year operation } \\
\qquad\left(€ \mathrm{ha}^{-1}\right)\end{array}$ & $\begin{array}{c}\text { CREA-OL } \\
\text { Five year operation } \\
\left(€ \mathrm{ha}^{-1}\right)\end{array}$ & $\begin{array}{l}\text { Annual cost } \\
\left(€ h a^{-1}\right)\end{array}$ & $\begin{array}{l}\text { Three year operation } \\
\qquad\left(€ h \mathrm{a}^{-1}\right)\end{array}$ & $\begin{array}{l}\text { CREA-AAM } \\
\text { Five year operation } \\
\left(€ \mathrm{ha}^{-1}\right)\end{array}$ & $\begin{array}{l}\text { Annual cost } \\
\left(€ \mathrm{ha}^{-1}\right)\end{array}$ \\
\hline $1^{\text {st }}$ & - & - & - & - & - & - \\
\hline $2^{\text {nd }}$ & - & - & - & - & - & - \\
\hline $3^{\text {rd }}$ & 189.15 & - & 189.15 & 249.70 & - & 249.70 \\
\hline $4^{\text {th }}$ & - & - & - & - & - & - \\
\hline $5^{\text {th }}$ & - & 4260.14 & 4260.14 & - & 1702.06 & 1702.06 \\
\hline $6^{\text {th }}$ & 189.15 & - & 189.15 & 249.70 & - & 249.70 \\
\hline $7^{\text {th }}$ & - & 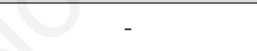 & - & - & - & - \\
\hline $8^{\text {th }}$ & - & - & - & - & - & - \\
\hline $9^{\text {th }}$ & 189.15 & - & 189.15 & 249.70 & - & 249.70 \\
\hline $10^{\text {th }}$ & - & 4260.14 & 4260.14 & - & 1702.06 & 1702.06 \\
\hline $11^{\text {th }}$ & - & - & - & - & - & - \\
\hline $12^{\text {th }}$ & 189.15 & - & 189.15 & 249.70 & - & 249.70 \\
\hline $13^{\text {th }}$ & - & - & - & - & - & - \\
\hline $14^{\text {th }}$ & - & - & - & - & - & - \\
\hline $15^{\text {th }}$ & 122.10 & 4260.14 & 4382.24 & 182.64 & 1702.06 & 1884.70 \\
\hline
\end{tabular}

Table 9. NET and competitiveness gap and values at the CREA-OLI and CREA-AAM operative units.

\begin{tabular}{lcc} 
& CREA-AAM \\
VAN $\left(€\right.$ ha $\left.^{-1}\right)$ & 9381.52 & 4346.04 \\
Competitiveness gap $\left(€ \mathrm{ha}^{-1}\right)$ & 9381.2 & 4346.04 \\
\hline Competitiveness gap $\left(€ \mathrm{ha}^{-1}\right.$ year $\left.^{-1}\right)$ & 843.78 & 390.89 \\
Competitiveness gap $\left(€\right.$ tree $^{-1}$ year $\left.^{-1}\right)$ & 2.02 & 3.91 \\
\hline
\end{tabular}




\section{References}

ASAE, 2003a. Standard EP496.2. American Society of Agricultural Engineers Publ., St. Joseph, MI, USA, pp. 367-372.

ASAE, 2003b. Standard D497.4. American Society of Agricultural Engineers Publ., St. Joseph, MI, USA, pp. 373-380.

Biondi P, 1999. Meccanica agraria. Le macchine agricole. Torino UTET, pp. 547-561

Corino L, Lavezzi A, Sansone L, Storchi P, Antonacci D, Coletta A, 2003. L'entretien des sol viticoles: enherbement. Progrés Aagricole et Viticole 120:134-138.

Corino L, Sansone L, Sandri P, 2004. Effetti dell'inerbimento sul comportamento vegeto-produttivo del vigneto. P.F. MiPAF "Inerbimenti e tappeti erbosi per la valorizzazione agricola, ambientale, ricreati- va e sportiva del territorio". Quaderni di divulgazione scientifica. 1:41-48.

ISTAT, 2012. Sesto censimento generale dell'agricoltura. www.istat.it Manfredi E, 1971. Raccomandazione A.I.G.R., IIIa sezione "denominazione, simbolo e unità di misura delle grandezza fondamentali relative all'impiego delle macchine in agricoltura, con particolare riguardo alle colture erbacee". Riv. Ing. Agr. 2:258-260.

MiPAAF, 2010. Rapporto di applicazione della condizionalità in Italia. http://www.agea.gov.it/portal/pls/portal/!PORTAL.wwpob_page.show ?_docname=2510175.PDF

Santilli E, Lombardo L, Varlaro ME, Nannelli R, Gagnarli E, Briccoli Bati C, 2011. Effectiveness of the GAEC cross compliance standard Maintenance of olive groves in good vegetative condition in avoiding the deterioration of habitats and land abandonment. Ital. J. Agron. 6(s1):e15. 
